\title{
Penerapan Model Quantum Teaching dengan Multimedia untuk Meningkatkan Hasi Belajar IPS tentang Kegiatan Jual Beli pada Siswa Kelas III SD Negeri Dilem Tahun Ajaran 2018/2019.
}

\author{
Khafidhatun Nafi'ah' ${ }^{1}$, Tri Saptuti. S ${ }^{2}$, M. Chamdani ${ }^{3}$ \\ 1,2,3 Universitas Sebelas Maret \\ khafidhatunnafiah@student.uns.ac.id
}

\section{Article History}

accepted 01/02/2020

\begin{abstract}
The objectives of this researchare to improve social studies learning outcomes about buying and selling activities through the application of the Quantum Teaching model with multimedia in third grade students of Dilem State Elementary School. This research is a collaborative classroom action research (CAR) conducted over three cycles with five meetings. Data collection techniques using observation, interviews, and tests. The result of this research show that the use of the Quantum Teaching model with multimedia can improve social studies learning outcomes about buying and selling activities in third grade students of Dilem State Elementary School in 2018/2019.
\end{abstract}

Keywords: quantum teaching, multimedia, sicial studies learning outcomes

\begin{abstract}
Abstrak
Penenlitian ini bertujuan untuk meningkatkan hasil belajar IPS dengan menerapakan model Quantum Teaching dengan multimedia di kelas III SD. Penelitian ini adalah penelitian tindakan kelas kolaboratif yang dilaksanakan selama tiga siklus dengan lima pertemuan. Teknik pengumpulan data menggunakan observasi, wawancara, dan tes. Hasil penelitian ini menunjukkan bahwa penerapan model Quantum Teaching dengan multimedai dapat meningkatakan hasil belajar IPS tentang kegiatan jual beli pada siswa kelas III SD Negeri ilem tahun ajaran 2018/2019.
\end{abstract}

Kata kunci: quantum teaching, multimedia, hasil belajar IPS 


\section{PENDAHULUAN}

Sekolah merupakan salah satu lembaga pendidikan formal yang berperan sebagai salah satu penunjang tercapainya tujuan pendidikan. Tujuan pendidikan nasional abad ke-21 hendaknya untuk mewujudkan cita-cita bangsa, yaitu masyarakat Indonesia yang sejahtera dan bahagia, dengan kedudukan terhormat dan setara dengan bangsa lain, melalui pembentukan masyarakat yang terdiri dari sumber daya manusia yang berkualitas, yaitu pribadi yang mandiri, berkemauan dan berkemampuan untuk mewujudkan cita-cita bangsa. Tujuan pendidikan nasional tersebut sejalan dengan tujuan yang hendak dicapai melalui pembelajaran IPS, yaitu untuk memahami dan mengembangkan pengetahuan, fakta, peristiwa, konsep, dan generalisasi serta mampu mengaplikasikan dalam kehidupan masyarakat, bangsa, dan negara (Susanto, 2014: 1).

Pembelajaran IPS di sekolah lebih menekankan pada aspek-aspek pengetahuan, sikap, dan keterampilan dari berbagai permasalahan yang ada di sekitar (Susanto, 2014: 6). Sedangkan menurut Gunawan (2013: 48) IPS adalah suatu bahan kajian yang terpadu yang merupakan penyederhanaan, adaptasi, seleksi, dan modifikasi yang diorganisasikan dari konsep-konsep dan keterampilan Sejarah, Geografi, Sosiologi, Antropologi, dan Ekonomi.

Proses Pembelajaran dapat diikuti dengan baik dan menarik perhaian siswa apabila guru dapat menggunakan atau menerapkan model pembelajaran yang sesuai dengan karakteristik pembelajaran. Model pembelajaran yang sesuai dengan IPS salah satunya adalah model Quantum Teaching. Model Quantum Teaching adalah model yang membangkitkan keaktifan siswa karena didasarkan pada pengalaman yang dialami siswa.

Model Quantum Teaching akan lebih bermakna pada saat pembelajaran jika didukung dengan adanya media pembelajaran, seperti multimedia. Oblinger (Munir, 2015: 2) berpendapat bahwa multimedia merupakan penyatuan dua atau lebih media komunikasi seperti teks, grafik, animasi, audio dan video dengan ciri-ciri interaktivitas untuk menghasilkan satu presentasi menarik. Hal itu ditegaskan oleh pendapat Mayer (2003) dalam Ercan (2014: 610) menjelaskan bahwa "Multi-media can be identified as an environment in which text, picture, soun, animation, video or a combination of these media are used for students to access information". Multi-media dapat didefinisikan sebagai lingkungan di mana teks, gambar, suara, animasi, video atau kombinasi media yang digunakan siswa untuk mengakses informasi.

Ditemukan fakta nilai rata-rata hasil belajar IImu Pengetahuan Sosial yang diperoleh siswa kelas III SD Negeri Dilem tergolong masih rendah. Rendahnya hasil belajar siswa dipengaruhi oleh beberapa faktor. pada saat pembelajaran masih terdapat beberapa siswa yang kurang memperhatikan penjelasan guru, terdapat siswa yang asik main sendiri, melamun, dan berbicara dengan teman disebelahnya maupun dibelakangnya. pembelajaran hanya terpusat pada guru, pada saat pembelajaran guru belum menerapkan model pembelajaran yang inovatif, pada saat pembelajaran masih terdapat siswa yang kurang berminat terhadap pembelajaran.

Berdasarkan analisis hasil yang dilakukan peneliti di kelas III SD Negeri Dilem pada mata pelajaran IPS pada nilai ulangan tengah semester, hasilnya masih banyak siswa yang nilainya di bawah KKM yaitu 73. Sedangkan siswa yang memperoleh nilai di atas KKM dengan rentang nilai 73-100 hanya dicapai oleh 8 siswa dari 26 siswa. ini berarti siswa yang memperoleh nilai di atas KKM hanya $31 \%$.

Kenyataan tersebut merupakan sesuatu yang perlu dicari jalan keluarnya agar hasil belajar IPS bisa lebih baik. Salah satunya alternatif yang diduga mampu untuk mengatasi masalah tersebut adalah melaui penerapan model Quantum Teaching. Model Quantum Teaching merupakan model pembelajaran yang yang mengutamakan proses pembelajaran yang aktif dan menyenangkan bagi siswa. 
Kusmana dalam penelitian yang dilakukan oleh Amirotun, Wahyudi, dan Suryandari (2013: 158-159) mengemukakan bahwa Quantum Teaching adalah prosedur pembelajaran yang dikembangkan dari suatu metode pembelajaran dengan rancangan dan fasilitas belajar yang menyenangkan, mengaktifkan, dan menjanjikan hasil belajar yang optimal.

Dengan demikian, model Quantum Teaching merupakan model pembelajaran yang meriah, menyenangkan, mengaktifkan siswa, yang diharapkan dapat meningkatkan hasil belajar siswa, khususnya dalam mata pelajaran IPS.

Menurut DePorter, Reardon, dan Nourie (2011: 33) dalam pelaksanaan pembelajaran Quantum Teaching dikenal dengan adanya TANDUR : Tumbuhkan, Alami, Namai, Demonstrasikan, Ulangi, Rayakan.

Shoimin (2014: 145) menjelaskan tentang kelebihan model Quantum Teaching, yaitu: a) dapat mengarahkan dan membimbing siswa ke arah berpikir yang sama; b) siswa lebih mudah dipusatkan kepada hal-hal yang dianggap penting oleh guru; c) tidak memerlukan keterangan yang banyak sebab melibatkan gerakan dalam kegiatan pembelajaran; d) proses pembelajaran berlangsung lebih nyaman dan menyenangkan; e) siswa dirangsang untuk aktif; f) guru terbiasa untuk berpikir kreatif; dan g) pelajaran yang diberikan guru mudah diterima dan dimengerti oleh siswa.

Berdasarkan uraian di atas, maka rumusan masalahnya adalah apakah penerapan model Quantum Teaching dengan Multimedia dapat meningkatkan hasil belajar IPS tentang kegiatan jual beli pada kelas III SD Negeri Dilem Tahun Ajaran 2018/2019?

Tujuan penelitian berdasar-kan rumusan masalah di atas yaitu meningkatkan hasil belajar IPS tentang kegiatan jual beli pada siswa kelas III SD Negeri Dilem Tahun Ajaran 2018/2019 melalui penerapan model Quantum Teaching dengan multimedia.

\section{METODE PENELITIAN}

Penelitian tinadakan kelas ini dilaksanakan di SD Negeri Dilem pada semester II tahun ajaran 2018/2019, yakni bulan Mei 2019. Subjek penelitian ini adalah siswa kelas III SD Negeri Dilem tahun ajaeran 2018/2019 yang berjumlah 26 siswa terdiri dari 10 siswa laki-laki dan 16 siswa perempuan. Sumber data dari penelitian ini adalah siswa, guru, dan dokumen.

Validitas ini menggunakan triangulasi sumber dan triangulasi teknik pengumpulan data. Tri-angulasi teknik pengumpulan data ini dilakukan dengan teknik tes, teknik observasi, dan wawancara. Sedang-kan triangulasi sumber data didasarkan pada sudut pandang siswa dan guru.

Pada penelitian ini terdapat teknik analisi data kuantitatif dan kualitataif. Teknik analisis data kuantitatif digunakan untuk menganalisis hasil belajar IPS siswa, sementara teknik analisi data kualitataif digunakan untuk menganalisis penerapan model Quantum Teaching dengan multimedia.

Indikator kinerja yang diharapkan tercapai dalam penelitian ini yaitu sebesar $85 \%$ untuk mengukur pelaksanaan langkah-langkah penerapan model Quantum Teaching dengan multimedia dan $85 \%$ untuk mengukur hasil belajar siswa dalam pembelajaran IPS.

Prosedur penelitian ini merupakan siklus kegiatan yang akan dilaksanakan selama tiga siklus, dengan lima pertemuan. Masing-masing siklus meliputi perencanaan, pelaksanaan, pengamatan, dan refleksi. Hal tersebut sesuai dengan pendapat Arikunto, Suhardjono, dan Supardi (2015: 42) dalam penelitian terdapat tahap pelaksanaan dimulai dari perencanaan, tindakan, observasi, hingga tahap refleksi. 


\section{HASIL DAN PEMBAHASAN}

Dalam pembahasan ini, akan dipaparkan mengenai hasil observasi terhadap kegiatan guru, kegiatan siswa, dan tes hasil belajar siswa dalam penerapan model Quantum Teaching dengan multimedia.

Hasil observasi oleh 3 observer terhadap guru pada penerapan model Quantum Teaching dengan multimedia dapat dilihat pada tabel berikut:

Tabel 1. Perbandingan Hasil Observasi terhadap Guru dan Siswa Siklus I-III

\begin{tabular}{|c|c|c|c|}
\hline \multirow{2}{*}{$\begin{array}{c}\text { Observasi } \\
\text { terhadap }\end{array}$} & \multicolumn{3}{|c|}{ Skor Rata-rata (\%) } \\
\cline { 2 - 4 } & $\begin{array}{c}\text { Siklus } \\
\text { I }\end{array}$ & $\begin{array}{c}\text { Siklus } \\
\text { II }\end{array}$ & $\begin{array}{c}\text { Siklus } \\
\text { III }\end{array}$ \\
\hline Guru & 74,65 & 84,03 & 90,28 \\
\hline Siswa & 74,65 & 83,68 & 90,63 \\
\hline
\end{tabular}

Berdasarkan tabel 1, di-ketahui bahwa proses pembelajaran di siklus I, siklus II, dan siklus III selalu mengalami peningkatan. Hasil capaian guru dalam mengajar pada sikus I yaitu $74,65 \%$, pada siklus II $84,03 \%$, dan pada siklus III $90,28 \%$. Hasil capaian siswa dalam pembelajaran pada siklus I yaitu $74,65 \%$, pada siklus II yaitu $83,68 \%$, dan pada siklus III mencapai $90,63 \%$.

Tabel 2. Perbandingan Hasil Tes Siklus I-III

\begin{tabular}{|c|c|c|}
\hline \multirow{2}{*}{$\begin{array}{c}\text { Siklu } \\
\text { s }\end{array}$} & \multicolumn{2}{|c|}{$\begin{array}{c}\text { Presentase } \\
\text { Ketuntasan }\end{array}$} \\
\cline { 2 - 3 } & T & BT \\
\hline I & $57,69 \%$ & $42,31 \%$ \\
\hline II & $78,85 \%$ & $21,15 \%$ \\
\hline III & $88,46 \%$ & $11,53 \%$ \\
\hline
\end{tabular}

Keterangan:

$\mathrm{T} \quad=$ Tuntas

BT = Belum Tunntas

Berdasarkan tabel 2 di atas, dapat disimpulkan bahwa presentase ketuntasan siswa juga meningkat dari $57,69 \%$ di siklus I, menjadi $78,85 \%$ di siklus II, dan $88,46 \%$ di siklus III.

Penelitian ini menunjukkan bahwa penerapan Quantum Teaching dengan multimedia yang di-laksanakan secara tepat dapat meningkatkan hasil belajar siswa kelas III SD Negeri Dilem khususnya pada mata pelajaran IPS. Hal itu sesuai dengan pendapat penelitian relevan yang dilakukan Amirotun, Wahyudi \& Suryandari (2013: 163) menyatakan bahwa model pembelajaran quantum teaching dengan multimedia dapat meningkatkan hasil belajar IPS. Dan didukung dengan penelitian yang dilakukan oleh Astiti (2016: 8) menyatakan bahwa penerapan model quantum teaching pada 
pembelajaran membuat aktivitas siswa menjadi lebih aktif dan berminat dalam pembelajaran IPS.

\section{SIMPULAN}

Berdasarkan hasil penelitian, dapat ditarik kesimpulan sebagai berikut: penerapan model Quantum Teaching dengan multimedia dapat meningkatkan hasil belajar IPS tentang kegiatan jual beli pada siswa kelas III SD Negeri Dilem tahun ajaran 2018/2019. Hal tersebut dapat dilihat dari presentase ketuntasan siswa yaitu $57,69 \%$ pada siklus I, $78,85 \%$ pada siklus II, dan $88,46 \%$ pada siklus III.

Saran peneliti bagi siswa hendaknya lebih fokus dan aktif dalam pembelajaran, berani bertanya tentang materi pembelajaran yang belum dipahami, dan percaya diri dalam menyampaikan pendapat sehingga proses pembelajaran menjadi lebih baik dan memperoleh hasil yang maksimal. Bagi guru sebaiknya lebih berusaha dalam mengarahkan siswa untuk fokus dan aktif dalam langkah model Quantum Teaching dengan multimedia agar siswa dapat menikmati suasana belajar dan lebih memahami materi yang disampaikan sehingga pembelajaran lebih bermakna dan hasil belajar siswa lebih maksimal. Bagi sekolah hendaknya menyediakan fasilitas, sarana, dan prasarana serta mendukung guru untuk berinovasi dalam menggunakan model dan media pembelajaran untuk meningkatkan kualitas pembelajaran. Bagi peneliti selanjutnya sebaiknya membuat kegiatan pembelajaran yang lebih inovatif dan kreatif sesuai dengan perkembangan ilmu pengetahuan dan teknologi. Salah satunya yaitu dengan menerapkan model quantum teaching dengan multimedia.

\section{DAFTAR PUSTAKA}

Amirotun, S., Wahyudi, Suryandari, K C. (2013). Penerapan Model Quantum Teaching dalam Peningkatan Pembelajaran IPS Siswa Kelas IV SD Negeri Sidomulyo. Jurnal:Kalam Cendekia, 4 (2) 158-159.

Arikunto, S., Suhardjono, dan Supardi. (2015). Penelitian Tindakan Kelas. Jakarta: Bumi Aksara

Astiti, V. (2016). Peningkatan Hasil Belajar IPS Melalui Model Quantum Teaching Siswa Kelas IV SDN Minomartani 1. Jurnal: Pendidikan Guru Sekolah Dasar. Edisi 28 tahun ke-5.

DePorter, B., Reardon, M., \&Singer-Nourine, S. (2011). Quantum Teaching. Bandung: PT MizanPustaka.

Ercan, O. (2015). The Effects Of Multimedia Learning Material On Students' Academic Achievement And Attitudes Towards Science Courses. Jurnal of Baltic Science Education, 13 (5) 610.

Gunawan, R. (2013). Pendidikan IPS; filosofi, konsep dan aplikasi. Bandung: Alfabeta. Munir. (2015). Multimedia: konsep dan aplikasi dalam pendidikan. Bandung: Alfabeta. Shoimin, A. (2014). 68 Model Pembelajaran Inovatif dalam Kurikulum 2013.

Susanto, A. (2014). Pengembangan Pembelajaran IPS di Sekolah Dasar. Jakarta: Kencana Prenada Media Group. 